\title{
Автоматизація розрахунків і конструювання тепло-масообмінних апаратів
}

\section{T. С. Снігур, А. О. Стукаленко}

Одеська національна академія харчових технологій, вул. Канатна, 112, Одеса, 65039, Україна

$\bowtie$ e-mail: snigur.tatyana@ukr.net

\begin{abstract}
Метою дослідження є моделювання робочих прочесів з урахуванням особливостей плівкових течій в тепломасообмінних апаратах і проведення дослідження сонячних регенераторів абсорбенту та випаровувальних охолоджувачів; на основі виконаного цииклу робіт отримання формульного набору для розрахунків і рекомендацій, щүо забезпечують дані для створення програмного забезпечення для автоматизації розрахунків $і$ конструювання таких систем.
\end{abstract}

Ключові слова: сонячний колектор; режимні параметри; тепло-масообмінний аппарат; програмне забезпечення; графічний інтерфейс.

\section{1 Вступ}

Сьогоднішній світ перейшов на новий етап життя, де головну роль виконує інформація, а також економіка, що будується на ній. Сучасний розвиток інформаційного суспільства безпосередньо пов'язаний з необхідністю збору, обробки і передачі величезних об'ємів інформації, перетворенням інформації у товар, як правило, значної вартості. Це стало причиною глобального переходу від індустріального суспільства до інформаційного. Поява всесвітньої мережі Інтернет, мобільних пристроїв та хмарних технологій спричинили масштабне зростання нового програмного забезпечення, міжнародних спілкувань у різних сферах науки і техніки.

Інформація є одним з найцінніших ресурсів суспільства поруч з традиційними матеріальними видами ресурсів, як нафта, метал, корисні копалини тощо, тому, процес переробки інформації, подібно до процесів переробки матеріальних ресурсів можна сприймати як технологію. Інформаційна технологія передбачає вміння грамотно працювати з інформацією, з обчислювальною технікою, з мобільною технікою, що використається для автоматизації інженерних розрахунків.

\section{2 Процеси трансформації сонячної енергії в сонячному газо-рідинному колекторі-регене- раторі}

У розділі описується математичне моделювання процесів в газо-рідинному колекторі-регенераторі $(\mathrm{CK} / \mathrm{P})$, прозоре покриття (ПП) якого виконане 3 полімерної багатоканальної плити, що має стільникову структуру. Така плита (рис. 3.1, позиція 1) може розглядатися як звичайне подвійне прозоре покриття, утворене двома еквідістантно розташованими полімерними пластинами 3 повітряним зазором між ними, а сам $\mathrm{CK} / \mathrm{P}$, таким чином, являє собою сонячний колектор 3 подвійним прозорим покриттям. Добре відомо, що використання подвійного ПП істотно знижує величину сумарного коефіцієнта втрат в СК [1], але зазвичай застосовується подвійне ПП у вигляді подвійного скла, що призводить до зростання ваги і габаритів СК i ускладнює конструкцію колектора в цілому. Використання багатоканальної полімерної плити практично не змінює ці показники, граючи в той же час традиційну роль «подвійного скла».

При виведенні рівнянь, зроблені допущення: режим роботи сонячного колектора стаціонарний; градієнтом температури теплоносіїв по периметру каналу можна знехтувати; температура кожного елемента СK/P змінюється тільки по напрямку руху теплоносія; властивості матеріалів СК/P і теплоносіїв не залежить від температури; поглинання сонячної енергії покриттями колектора не впливає на втрати колектора в цілому.

Коефіцієнти тепловіддачі (іх радіаційні і конвективні складові) можна розрахувати за відомими виразами (схема $\mathrm{CK} / \mathrm{P}$ на рис. 1Б). Тепловий ланцюг для СК/Р приведено на рис. 1.

Для зовнішньої поверхні колектора з боку сонця (покриття ВП - ОС, тут індекси: НБ - для небосхилу; НС - для навколишнього середовища, ВП - для верхнього прозорого покриття), можна використовувати залежно:

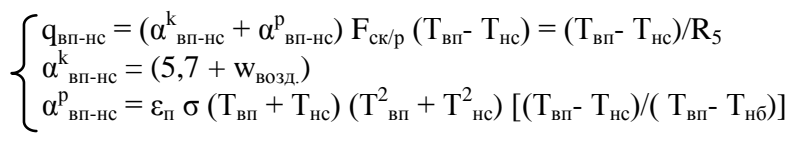


де: $\alpha^{\kappa}$ и $\alpha^{p}-$ конвективна та радіаційна складові коефіцієнта тепловіддачі, Вт/( $\left.\mathrm{M}^{2} \cdot \mathrm{K}\right) ; \mathrm{w}$ - швидкість вітру над ВП колектора, м/c; $\varepsilon_{\Pi}-$ ступінь чорноти; $\sigma$ постійна Стефана-Больцмана, Вт/( $\mathrm{m}^{4} \cdot$ град $\left.^{2}\right) ; \mathrm{R}_{5}$ - термічний опір на даній ділянці.

Для всіх внутрішніх порожнин колектора:

- покриття НП-ВП, повітряний зазор в багатоканальній полімерній плиті ПП, тут індекси: ВП - для верхнього прозорого покриття; НП - для нижнього прозорого покриття);

- покриття А-НП, тут індекси: НП - для нижнього прозорого покриття; А - для поверхні абсорбера), можна використовувати залежно:

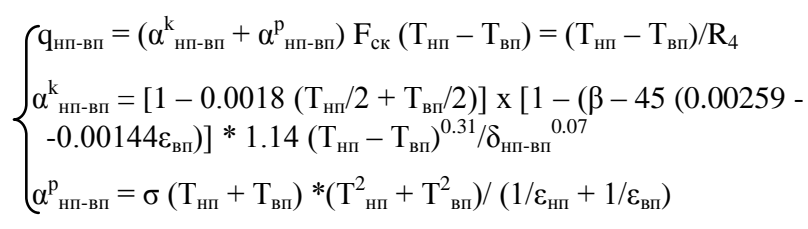

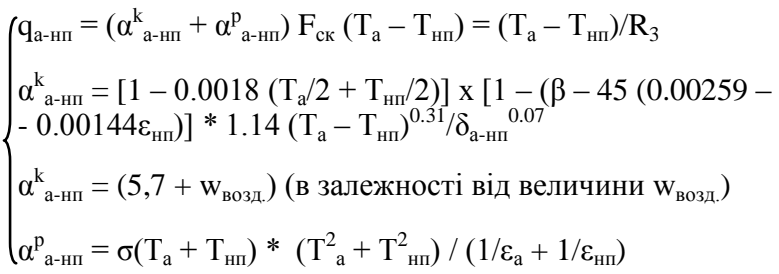

де: $\beta$ - кут нахилу СК до горизонту, град; $\delta_{\text {анп }}-$ відстань між відповідними поверхнями, мм.

Залежно від типу CK/P, з «природною» тягою, яка забезпечується сонячним прогріванням повітря або 3 вентилятором, розташованим на подачі повітря в колектор, в системі рівнянь 3. слід використовувати одне 3 двох наведених рівнянь для розрахунку величини $\alpha_{\mathrm{a}-н п}^{\mathrm{k}}$.

Для теплоізоляції (A-I3) термічний опір R1 визначається теплопровідністю обраного матеріалу теплоізоляції. Для зовнішньої поверхні колектора з боку дна (I3НC) можна використовувати формули:

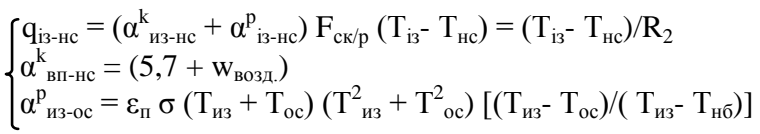

де $\alpha_{\mathrm{a}-ж}^{\mathrm{k}}, \alpha_{\mathrm{a}-\mathrm{H}}^{\mathrm{k}}, \alpha_{\text {нп-вп }}^{\mathrm{k}}, \alpha_{\text {вп-нс }}^{\mathrm{k}}, \alpha_{\text {iз-нс }}^{\mathrm{k}}-$ конвективні складові тепловіддачі від бічних і нижньої поверхні пластини теплоприймача (абсорбера) до рідини (теплоносія, в даному випадку до розчину абсорбенту); теплових втрат від бічних поверхонь пластини теплоприймача (абсорбера) і поверхні рідини в повітряної частини робочого каналу СК/Р (А - НП); теплових втрат між нижньою і верхньою поверхнею прозорого покриття (НП - ВП); теплових втрат з поверхні прозорого покриття в навколишнє середовище (ВП - НС); теплових втрат від «дна» теплоізоляції в навколишнє середовище (I3 - HC) $\mathrm{BT} /(\mathrm{м} 2 \cdot \mathrm{K})$. $\alpha_{\text {a-нп, }}^{\mathrm{p}}, \alpha_{\text {нп-вп }}^{\mathrm{p}}, \alpha_{\text {вп-нс }}^{\mathrm{p}}, \alpha_{\text {iз-нс }}^{\mathrm{p}}-$ радіаційні складові теплових втрат від бічних поверхонь пластини теплоприймача (абсорбера) і поверхні рідини в робочому каналі СК/P (А-НП); теплових втрат між нижньою і верхньою поверхнею прозорого покриття (НП-ВП); теплових втрат 3 поверхні прозорого покриття в навколишне середовище (ВП-НС); теплових втрат від «дна» теплоізоляції в навколишнє середовище (I3-НC) Вт/(м2·К) [2].

Термічні опори основних елементів СК / Р визначають коефіцієнт втрат за формулою $U_{\mathrm{i}}=1 / R_{\mathrm{i}}$, где $U_{i}-$ коефіцієнт втрат на кожній ділянці СК, Вт/(м2·град); $R_{\mathrm{i}}-$ термічний опір на кожній ділянці СК, (м2·К)/Вт.

Величина сумарного коефіцієнта втрат для $\mathrm{CR} / \mathrm{H}$ (рисунок 1) визначається формулою:

$$
U_{\Sigma}=1 /\left(R_{1}+R_{2}+R_{3}+R_{4}+R_{5}\right)
$$

$$
\text { де } U_{\Sigma}=\frac{1}{\frac{1}{\alpha^{k}{ }_{B n-H c}+\alpha_{b n-H c}^{p}}+\frac{1}{\alpha_{n n-6 n}^{k}+\alpha_{H n-6 n}^{p}}+\frac{1}{\alpha_{a-H n}^{k}+\alpha_{a-H n}^{p}}}+\frac{\lambda_{i 3}}{\delta_{i 3}}
$$

Тут основне значення, при правильному виборі типу i розрахунку товщини теплоізоляції, мають термічні опори на ділянках R3, R4, i R5, що визначають теплові втрати колектора-регенератора.

На практиці вводиться поняття ефективності сонячного колектора $F^{\prime}$, представляє собою відношення термічного опору переносу теплоти від поглинання пластини теплоприймача СК до навколишнього повітря до опору переносу теплоти від рідини до навколишнього повітря. Величину $F^{\prime}$ для розглянутої конструкції СК можливо розрахувати за формулою:

$$
F^{\prime}=\frac{1}{\frac{\delta_{1-1} \cdot U_{\Sigma}}{\pi \cdot D \cdot \alpha_{\mathscr{N}}}+\frac{\delta_{1-1}}{D+\left(\delta_{1-1}-D\right) \cdot f_{p}}},
$$

де $\delta_{l-1}-$ відстань між центрами сусідніх каналів теплоприймача (абсорбера), м; $D$ - еквівалентний діаметр робочого каналу, який визначається його основними габаритами $\delta_{1-1}$ і $\delta_{1-2} ; \alpha_{\text {ж }}-$ коефіцієнт тепловіддачі від стінки U-подібного каналу до рідини, Вт/(м²· $)$, (Зазвичай в розрахунках приймають величину $\alpha_{ж} \approx 300$ для природної $i \approx 1500$ для вимушеної конвекції; величина коефіцієнта тепловіддачі від стінки U-подібного каналу до повітря істотно менше; $f_{\mathrm{p}}$ - ефективність ребра прямокутного профілю, $f_{\mathrm{p}} \approx 0,9$.

Коефіцієнт корисної дії СК можна розрахувати за формулою:

$$
\eta=\tau \cdot \varepsilon_{1} \cdot F^{\prime}-U_{\Sigma} \cdot F^{\prime} \cdot\left[0.5 \cdot\left(t_{\oiiint 1}+t_{\oiiint 2}\right)-t_{0}\right] / I
$$

де $t_{\text {ж1 }}$ - температура рідини на вході в $\mathrm{CK},{ }^{\circ} \mathrm{C}$;

$t_{\nsim 2}$ - температура рідини на виході з $\mathrm{CK},{ }^{\circ} \mathrm{C}$.

Якщо $\mathrm{U}_{\Sigma}$ i $F^{\prime}=$ const, залежність $\eta$ від $\left[0.5 \cdot\left(t_{ж 1}+t_{ж 2}\right)-t_{0}\right] / I$ являє собою пряму лінію. Величина $T_{\text {пр. }}=\left[0.5 \cdot\left(t_{\text {ж1 }}+t_{\text {ж2 }}\right)-t_{0}\right] / I-$ це приведена температура. 


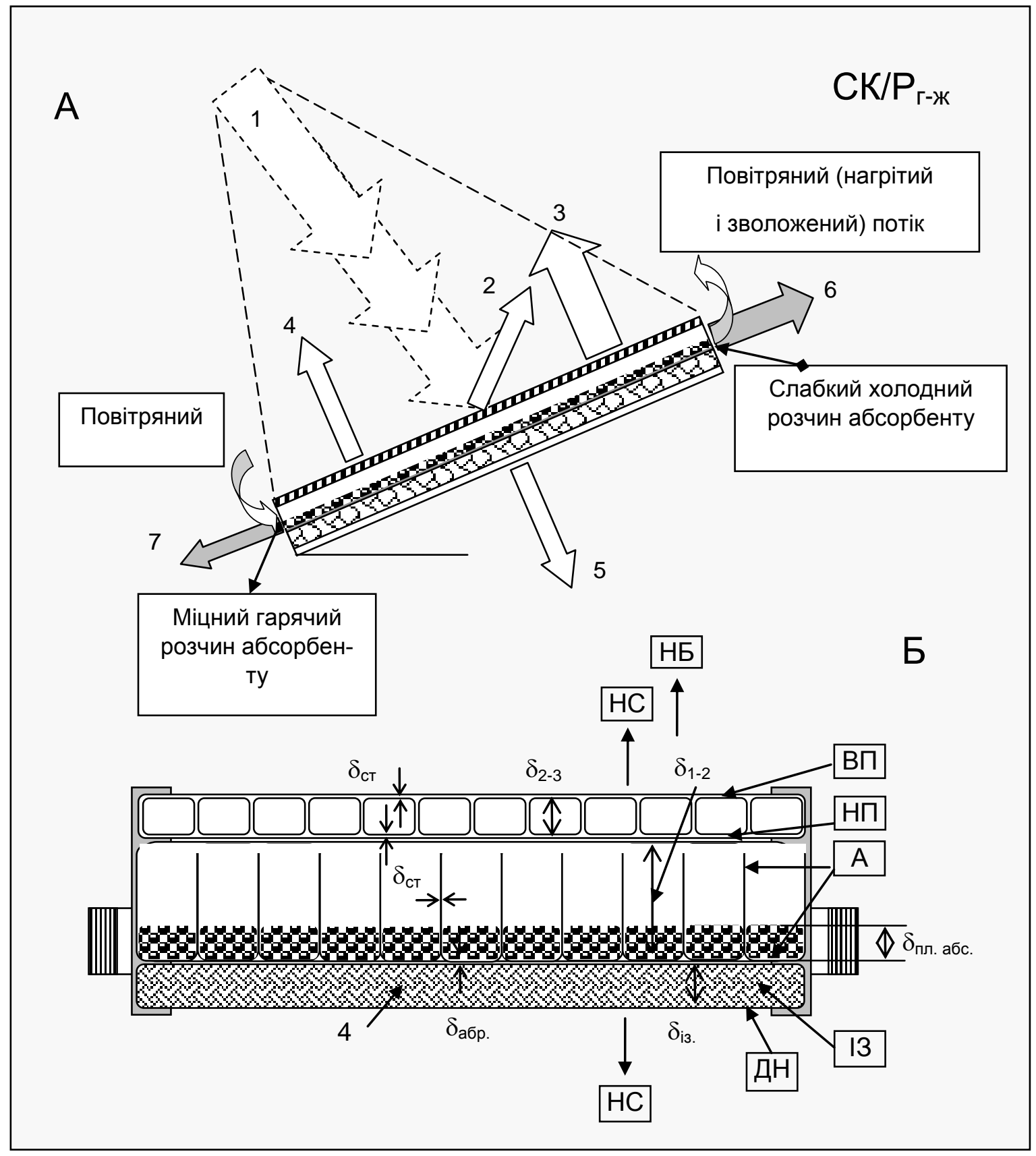

A - Характерний тепловий ланцюг СК/Р. Позначення до рисунку 1а:

1 - сонячна радіація; 2 - втрати відображенням від ПП; 3 - сумарні конвективні втрати; 4 - сумарні радіаційні втрати; 5 - втрати в теплоізоляції; 6 - винос теплової енергії з колектора повітряним потоком; 7 - винос теплової енергії з колектора потоком абсорбенту.

Б - компоновка СК/Р. Позначення до рисунку 1б:

1 - теплообмінник (абсорбер); 2 - нижнє прозоре покриття (прозора ізоляція НП); 3 - верхнє прозоре покриття (прозора ізоляція ВП); 4 - теплоізоляція днища; ОС - навколишнє середовище; НБ - небосхил; $\delta$ - геометричні розміри основних елементів колектора-регенератора.

Рисунок 1 - До розрахунку теплових втрат в газо-рідинному сонячному колекторі з гравітаційним плином плівки абсорбенту. 


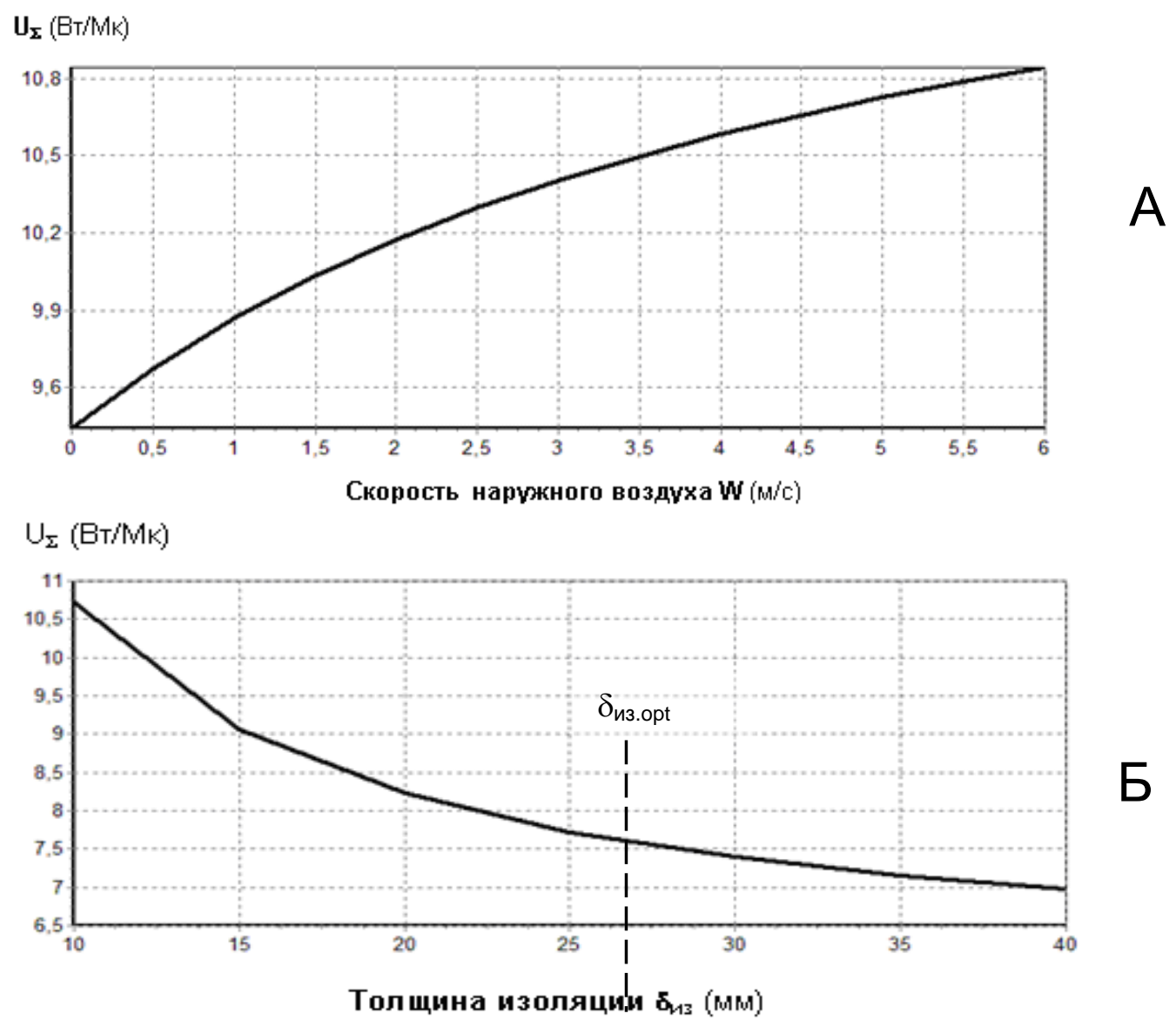

Рисунок 2 - Залежність коефіцієнту сумарних теплових втрат в СК: А - від швидкості зовнішнього повітря; Б - від товшини ізоляції СКГ-ж

\section{Висновки}

Автоматизація розрахунків ніколи не втратить актуальності в суспільстві інженерів, технологів, науковців. Можливість точних, більш швидких електронних розрахунків лиш збільшила їх популярність, дало нові можливості. Рішення саме цієї проблеми було поставлено основоположним.

Для вирішення проблеми автоматизації розрахунків, збільшення точності та швидкості цих розрахунків створене програмне забезпечення 3 достатнім функціоналом.

\section{Література}

1. Антонова, А. Р. Теоретичне та експериментальне дослідження процесів у газорідинних сонячних колекторах-регенераторах альтернативних холодильних сис- тем [Текст] : дис. канд. техн. наук : 05.14.06: захищена 29.09.2014 : затвердж. 25.11.2014 / Альфія Раісівна Антонова. - Одеса, 2014. - 205 с. - Бібліогр.: с. 186-205. 04200204434.

2. Антонова А.P. Солнечные многоступенчатые абсорбционные холодильные системы на основе тепломассообменных аппаратов пленочного типа [Текст] / А.В. Дорошенко, А.Р. Антонова, К.В. Людницкий // Холодильна техніка та технологія. - 2015. - 51 (2). C. 25-31.

3. Антонова А.Р. Разработка и эколого-энергетический сравнительный анализ парокомпрессионных и солнечных абсорбционных схем систем кондиционирования воздуха. [Текст] / А.В. Дорошенко, А.Р. Антонова, Л.В. Иванова // Проблемы региональной энергетики. 2017. - 3 (35). - C. 69-84.

\footnotetext{
Отримана в редакції 18.12.2017, прийнята до друку 07.02.2018
} 


\section{Automation of calculations and design of heat-mass-exchange units}

T. S. Snigur, A. O. Stukalenko

Odesa National Academy of Food Technologies, 112 Kanatna str., Odesa, 65039, Ukraine

The purpose of the study is to simulate workflows, taking into account the peculiarities of film flows in heat-mass exchange machines, and conducting research on solar regenerators of absorbent and evaporative coolers; on the basis of the completed work cycle, obtaining a set of formulas for calculations and recommendations providing data for the creation of software for the automation of calculations and the design of such systems.

Keywords: solar collector; regime parameters; heat mass-exchange unit; Software; graphical user interface.

\section{References}

1. Antonova, A. R. (2014) Teoretichne ta eksperimentalne doslIdzhennya protsesIv u gazorIdinnih sonyachnih kolektorah-regeneratorah alternativnih holodilnih sistem: dis. kand. tehn. nauk : 05.14.06: zahischena 29.09.2014 : zatverdzh. 25.11.2014. Odesa, 205 s. (in Ukrainian)

2. Doroshenko A.V., Antonova A. R., Lyudnitskiy K.V. (2015) Solnechnyie mnogostupenchatyie absorbtsionnyie holodilnyie sistemyi na osnove teplomasso-obmennyih apparatov plenochnogo tipa. Refrigeration Engineering and technology, 51 (2). 25-31. (in Russian)

3. Doroshenko A.V., Antonova A.R., Ivanova L.V. (2017) Razrabotka i ekologo-energeticheskiy sravnitelnyiy analiz parokompressionnyih i solnech-nyih absorbtsionnyih shem sistem konditsionirovaniya vozduha. Problemyi regionalnoy energetiki, 3 (35), 69-84. (in Russian)

Received 18 December 2017 Approved 02 February 2018 Available in Internet 27 February 2018 